\section{Dispositivo digital: relato de experiência na produção de objeto de aprendizagem pedagógica}

\author{
Digital device: experience report in the production \\ of pedagogical learning object
}

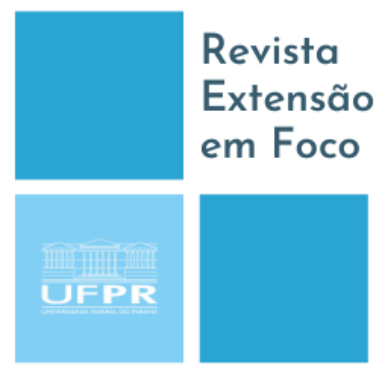

ISSN 2358-7180

\author{
Francisco Lindoval de Oliveira ${ }^{1}$, Diego de Oliveira da Cunha ${ }^{2}$
}

\begin{abstract}
RESUMO
O presente artigo tem como objetivo relatar o processo de produção de Objeto de Aprendizagem, especificamente um dispositivo digital com finalidade de ser utilizado em âmbito educacional, que colabora com a prática das ferramentas tecnológicas aplicadas na melhoria da qualidade da educação. Foi produzido um dispositivo utilizando diversas ferramentas digitais que incluíam áudio, vídeo, trilha sonora e animações. O objetivo de utilizar mais de uma ferramenta era alcançar os diversos níveis de aprendizagens do público alvo. Foi apresentado de forma dinâmica e objetiva de forma a despertar nos colegas acadêmicos, interesse em conhecer mais acerca das ferramentas oferecidas pelo G Suite For Education by Google. Para que o dispositivo fosse produzido utilizamos o aplicativo rawshorts, esse objeto de aprendizagem cria dispositivos animados no estilo de multimídia, concentrando áudio, vídeo, figuras, cores, animações e vozes dos autores. Como resultado principal, o dispositivo foi publicado livremente no YouTube. Resultou também em uma profunda reflexão onde percebemos que é possível produzir material didático digital utilizando qualquer assunto, a partir da criatividade e do conhecimento dos docentes. A participação ativa de outros grupos foi muito importante, pois comentavam o que sentiam ao reproduzir o dispositivo, de forma crítica e construtiva.
\end{abstract}

Palavras-chave: Objeto de aprendizagem. Dispositivo digital. Ferramentas tecnológicas.

\title{
ABSTRACT
}

This article aims to report the learning object production process, specifically a digital device with the purpose of being used in the educational field, which collaborates with the practice of technological tools applied to improve the quality of education. A device was produced using several digital tools that included audio, video, soundtrack and animations. The objective of using more than one tool was to reach the different levels of learning of the target audience. It was presented in a dynamic and objective way in order to awaken in academic colleagues, interest in knowing more about the tools offered by G Suite For Education by Google. For the device to be produced we used the rawshorts application, this learning object creates animated devices in the style of multimedia, concentrating audio, video, figures, colors, animations and voices of the authors. As a main result, the device was published freely on YouTube. It also resulted in a deep reflection where we realized that it is possible to produce digital didactic material using any subject, based on the creativity and knowledge of the teachers. The active participation of other groups was very important, as they commented on how they felt when reproducing the device, in a critical and constructive way.

Keywords: Learning object. Digital device. Technological tools.

\footnotetext{
${ }^{1}$ Especialista em Planejamento, Implementação e Gestão da EAD. Universidade Federal Fluminense (UFF), Niterói, Rio de Janeiro, Brasil. E-mail: francisco.nepitaguai@hotmail.com. Orcid: http://orcid.org/0000-0001-5993-5503

${ }^{2}$ Mestre em Administração. Universidade do Grande Rio Professor José de Souza Herdy (UNIGRANRIO), Rio de Janeiro, Rio de Janeiro, Brasil. E-mail: adm.diegoolivei@gmail.com. Orcid: http://orcid.org/0000$\underline{0002-0738-046 \mathrm{X}}$
} 


\section{INTRODUÇÃO}

A utilização de materiais didáticos tem sido uma forma de complementar as aulas, palestras e oficinas em âmbito pedagógico, contudo, o cenário escolar tende a se transformar com o passar do tempo, trazendo um novo ambiente contemporâneo além de associar tradicionais ferramentas didáticas com tecnologias digitais.

No intuito de se adequar ao novo contexto que a era digital vem trazendo, a escola precisa se inserir e repensar suas metodologias, currículo e ferramentas pedagógicas. Novos Objetos de Aprendizagem que englobam a tecnologia podem trazer recursos colaborativos para o ensino aprendizado dos alunos, explorando novas possibilidades de ensinar com tecnologia (BEIRA; NAKAMOTO, 2016).

Como prevê os Parâmetros Curriculares Nacionais (PCNs), a escola precisa aderir competências e habilidades desenvolvidas com uso da tecnologia, tendo em um dos seus principais conceitos a utilização computacional a fim de facilitar e incorporar ferramentas digitais específicas nas atividades do cotidiano escolar (BRASIL, 2000).

Dessa forma, o presente artigo tem como objetivo relatar o processo de produção de Objeto de Aprendizagem (AO), especificamente um dispositivo digital com finalidade de ser utilizado em âmbito educacional. Evidenciando o uso desse recurso como agente pedagógico e uma ampliação de possibilidades didáticas, inserindo essa ferramenta como forma de complementar ao material didático.

O dispositivo digital produzido tem como característica a utilização dinâmica, interativa e lúdica das mídias digitais. Esse OA pode ser produzido em diferentes contextos, mudando apenas o assunto a ser lecionado. As tecnologias escolhidas foram o áudio, o vídeo e animação digital reunidos em um único dispositivo, sendo produzida uma multimídia digital educativa e lúdica.

Nesse sentido, destacamos o dispositivo digital como um heterogêneo material didático onde a interação perpassa tradicionais ferramentas de aprendizagem, causando positivos impactos educativos e uma alusiva apresentação de competências e conteúdos.

\section{LINGUAGEM MULTIMÍDIA NA EDUCAÇÃO}


A utilização de tecnologia no meio educacional e pedagógico está em constante crescimento, sendo um acelerado avanço das mídias digitais que estão cada vez mais sendo inseridas nas salas de aulas. Essas ferramentas multimídias se fazem presentes no dia a dia dos alunos e dos professores, sendo utilizado áudio, vídeo, animações, mídias sociais dentre outros. Toda essa tecnologia traduz o objetivo de colaborar com metodologias e práticas pedagógicas que o professor traz em sala de aula, firmando um novo cenário educacional.

Para compreender a importância da linguagem multimídia no ensino, Andersen (2016, p. 23) define como "uma expressão cunhada para definir a combinação de sistemas semióticos verbais, sonoros e imagéticos, em meios digitais. É uma combinação não justaposta, mas que se realiza de forma integrada para construir sentido".

A partir da definição citada, percebe-se que multimídia é um recurso muito poderoso que pode colaborar no maior envolvimento do aluno, na contextualização didática tecnológica e o estímulo a criatividade. Nesse contexto, Zunguze et al. (2017) e Rossoni et al. (2020) evidenciam o princípio adaptativo do ensino onde o aluno pode criar diferentes caminhos de aprendizagem inclusive na utilização da multimídia na educação, sendo essas verdadeiras trajetórias de aprendizagem.

É notório que cada estudante tende a preferir uma determinada mídia devido ao detrimento de outra, contudo, cada estudante possui um perfil e estilo diferente, dessa forma a multimídia engloba a integração midiática almejando o alcance de cada discente, disputando mais entusiasmos e interação, além de ser uma nova estratégia didática (OCEPEK et al., 2013). É importante frisar que a multimídia é um conjunto de tecnologias que tem o intuito de contribuir com ensino aprendizado, além de ser um material didático digital (MERABET; SILVA; GONÇALVES; BARROS, 2020). Todavia, a educação se beneficia desse recurso tecnológico, mas não substitui o papel do professor como mediador pedagógico. Nessa contribuição, a participação ativa dos alunos em conjunto com o professor é muito importante, sendo que:

É bom que [o preceptor] faça trotar essa inteligência [a da criança] à sua frente para lhe apreciar o desenvolvimento e ver até que ponto deve moderar o próprio andar, pois em não sabendo regular a nossa marcha tudo estragamos. (MONTAIGNE, 1972, p. 81).

A incorporação de uma tecnologia aos processos educacionais passa pela compreensão das características constitutivas desse novo meio, de suas potencialidades e 
limitações em relação às formas de interação e construção de significados. Assim, tornase necessário que o professor utilize a tecnologia na condição de sujeito ativo, protagonista da ação, de modo que possa analisar a efetividade das contribuições desse suporte para a criação de experiências educativas significativas e relevantes para os aprendizes (ALMEIDA, 2007, p. 159).

\section{OBJETO DE APRENDIZAGEM PEDAGÓGICO}

Dentre tantas formas de utilizar a tecnologia no meio acadêmico, novas formas de criar recursos educacionais foram propostas. Em destaque, a criação de recursos digitais denominados Objetos de Aprendizagem (OA), passaram a ser construídos ao longo da era digital como formas de auxiliar o aprendizado, a resolução de problemas e principalmente a inovação metodológica com a utilização desses objetos (CUNHA et al., 2019).

Para Cunha et al. (2020), os OAs podem ser totalmente diversificados, desde objetos analógicos utilizando materiais tradicionais como o papel, recorte, bricolagem dentre outros meios pedagógicos, até a utilização digital com ajuda das tecnologias como computadores, celulares, tablets configurados com alguma multimídia.

Os OAs assumem um importante papel, pois corroboram com a ideia de diversificar a aprendizagem e o material didático.

O Objeto de Aprendizagem (OA) apresenta-se como uma vantajosa ferramenta de aprendizagem e instrução, a qual pode ser utilizada para o ensino de diversos conteúdos e revisão de conceitos. A metodologia como a qual o OA é utilizado será um dos fatores-chave a determinar se a sua adoção pode ou não levar o aluno ao desenvolvimento do pensamento crítico (AGUIAR; FLORES, 2014, p. 12).

É importante refletir que o OA é um recurso interativo, a utilização digital é cada vez maior devido a novas soluções encontradas na diversidade didática e os elementos contidos nessa ferramenta podem ser textos eletrônicos, figuras digitais, áudio, vídeo, animações, multimídias integradas dentre outros. Sendo uma predominante característica do OA a simplicidade, clareza e objetividade no recurso (CASTRO et al., 2002).

Para além, os OAs auxiliam na compreensão de conteúdos e conceitos mais complexos principalmente quando existe animação ou forma lúdica nesse objeto. 
Segundo Aguiar e Flores (2014), Cunha et al. (2019) e Rossoni et al. (2020), o professor pode utilizar recursos interativos no formato de vídeo, quando existe a intenção de explorar um conceito ou conteúdo de maior complexidade em sala de aula, ressaltando assim, a característica e a funcionalidade que o OA exerce de facilitar o ensino aprendizado do aluno.

Segundo Burn e Durran (2007) e Severiano Júnior (2020), a fundamentação para criação do dispositivo nasce de um pressuposto de criar e desenvolver uma compreensão crítica sobre um determinado assunto, partindo desse conceito para a construção midiática, o dispositivo digital surge da junção da multimídia com a produção do OA.

Para concretizar a ideia de dispositivo e compreender o quanto esse recurso é importante para o meio educacional, Morgado (2013), nos brinda dizendo que:

Faz-se necessário pensar sobre as abordagens dos dispositivos (tecnologias) digitais neste novo cenário singular de cibercultura, os quais podem potencializar o desenvolvimento do processo de formação da geração digital por meio de um currículo, que compreenda essa revolução social tecnológica e os fenômenos empreendedores neles inseridos, configurando-se um novo cenário alavancado pela colaboração e conectividade. (MORGADO, 2013, p. 167).

Assim, o dispositivo digital compõe uma categoria de recursos que podem ser utilizados em sala de aula, trabalhando ativamente com os alunos, melhorando a interação com assuntos e conteúdos pedagógicos, além de facilitar a compreensão da diversidade de assuntos.

\section{DETALHAMENTO DAS ATIVIDADES}

Foi produzido um dispositivo utilizando diversas ferramentas digitais que incluíam: áudio, vídeo, trilha sonora e animações. O objetivo de usar mais de uma ferramenta era alcançar os diversos níveis de aprendizagens do público alvo. Foi apresentado de forma dinâmica e objetiva de forma a despertar nos colegas acadêmicos, interesse em conhecer mais acerca das ferramentas oferecidas pelo G Suite For Education by Google.

O $G$ Suite For Education by Google, é um conjunto de ferramentas disponibilizadas pelo Google, de forma gratuita, que podem ser acessadas pelo computador ou até por smathphones. As ferramentas incluem a caixa de e-mail, drive para armazenamento em nuvem de diversos arquivos, produção de documentos que podem ser 
compartilhados, apresentações com animações, agenda para marcação de eventos e ainda confecção de planilhas.

Iniciamos o vídeo do dispositivo com uma pergunta narrada nas vozes dos produtores e com avatares dos mesmos, para que o olhar do público se voltasse para esse recurso, o avatar como lúdico. Para os jovens, está em alta a criação de avatares e "memes" como forma de animar o estudo e facilitar a aprendizagem, envolvendo todos em uma atividade criativa e lúdica. A pergunta feita (Figura 1) propunha uma reflexão acerca das próprias atitudes de cada acadêmico enquanto professor, e se tais atitudes propiciavam melhor aprendizado.

Figura 1 - Tela inicial do dispositivo

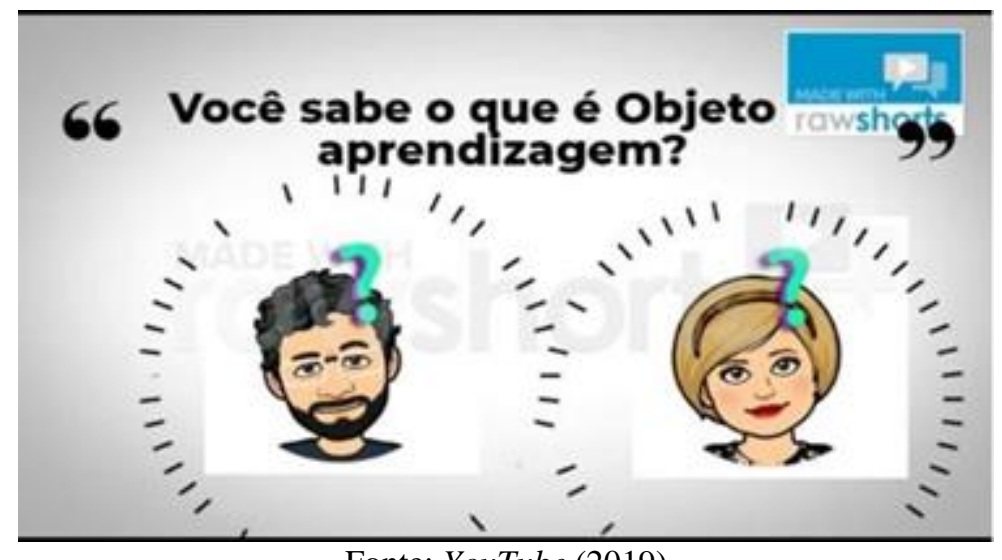

Fonte: YouTube (2019)

https://www.youtube.com/watch?v=HqkFzUrX5IQ\&feature=youtu.be

Na sequência da apresentação, inserimos o G Suite For Education by Google, conforme pode ser observada na Figura 2, através de imagens animadas, música de fundo e a explanação breve das ferramentas nas vozes dos criadores.

Figura 2 - Interatividade do dispositivo

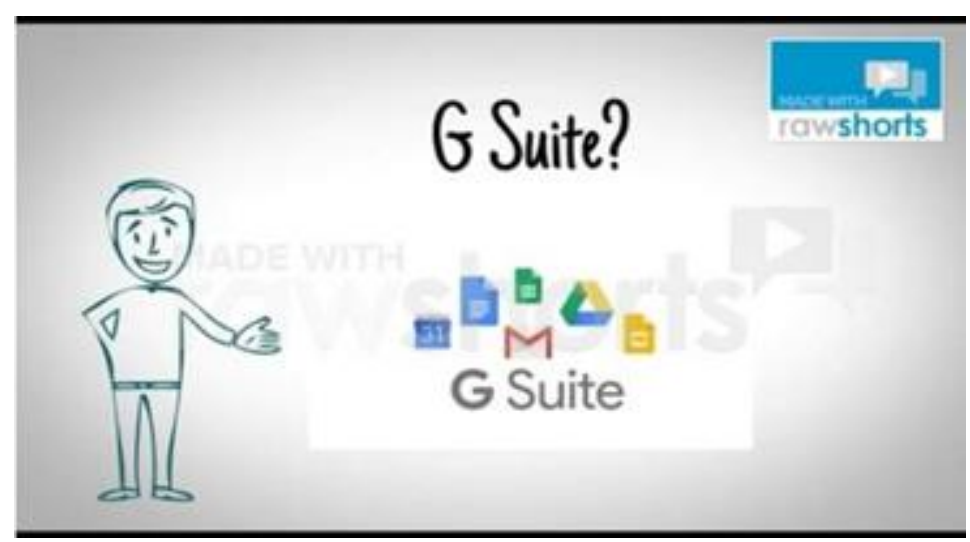

Fonte: YouTube (2019) 
https://www.youtube.com/watch?v=HqkFzUrX5IQ\&feature=youtu.be

A intenção nesta parte do vídeo era exibir quais ícones estão disponíveis no pacote pelo Google, como incentivo para o trabalho colaborativo na educação.

Na sequência, utilizamos os moldes dos recursos, em cada passagem um tipo de informação que pudesse despertar o interesse em utilizar as ferramentas, e, sobretudo mostrar que elas estão acessíveis para professores e acadêmicos e dispensa qualquer tipo de formação específica na área de tecnologia (Figura 3).

Figura 3 - Animação dinâmica do dispositivo

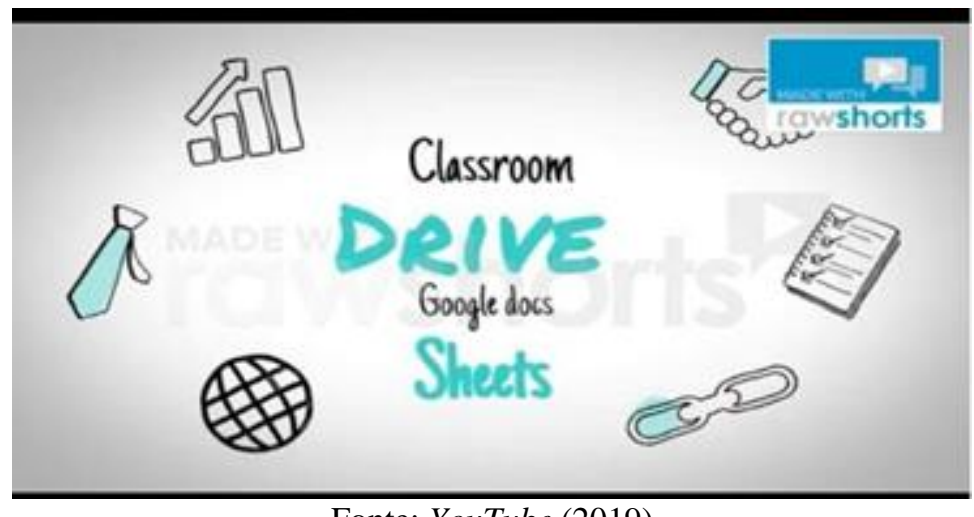

Fonte: YouTube (2019)

https://www.youtube.com/watch?v=HqkFzUrX5IQ\&feature=youtu.be

Por fim, na última parte do vídeo (Figura 4), buscamos instigar o professor a se autoavaliar e descobrir o que pode ser feito para melhoria de suas práticas em sala de aula.

Figura 4 - Contextualização final do dispositivo

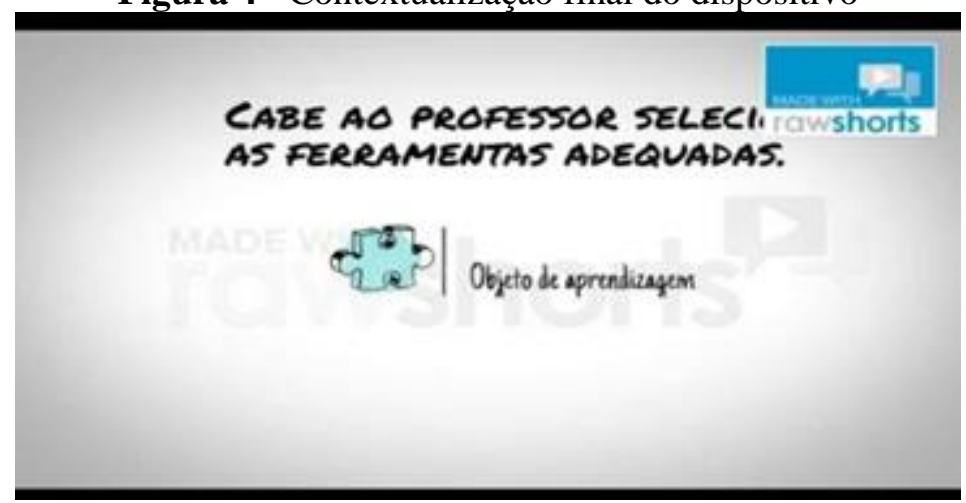

Fonte: YouTube (2019)

https://www.youtube.com/watch?v=HqkFzUrX5IQ\&feature=youtu.be

\section{ANÁLISE E DISCUSSÃO DO RELATO}


Para que o dispositivo fosse produzido utilizamos o aplicativo rawshorts, esse objeto de aprendizagem cria dispositivos animados no estilo de multimídia, concentrando áudio, vídeo, figuras, cores, animações e vozes dos autores.

Como resultado principal, o dispositivo foi publicado livremente no YouTube gerando o link https://www.youtube.com/watch?v=HqkFzUrX5IQ\&feature=youtu.be. A apresentação do dispositivo produzido pelos alunos, foi exibido mediante um seminário virtual, organizado no aplicativo WhatsApp, onde cada participante assinava sua contribuição acerca do dispositivo apresentado, tal contribuição incluía críticas e apreensões acerca do OA mediado pelo professor orientador, que deve guiar o aluno através dos caminhos e processos necessários para o seu desenvolvimento pessoal, dandolhe suporte ao seu aprendizado e à resolução de problemas.

A produção do dispositivo resultou também em uma profunda reflexão onde percebemos que é possível produzir material didático digital utilizando qualquer assunto, a partir da criatividade e do conhecimento dos docentes. A participação ativa de outros grupos foi muito importante, pois comentavam o que sentiam ao reproduzir o dispositivo, de forma crítica e construtiva.

Reafirmamos que todo contexto tecnológico digital é extremamente positivo, relevante e contém um favorável cenário na atualidade. Contudo, o professor desenvolve importante papel de mediador do conhecimento, que não é de propor soluções, mas de intermediar e facilitar o processo de ensino e aprendizagem para que a informação se transforme em conhecimento e gere novas aprendizagens. Este professor mediador precisa estar apto a conhecer as tecnologias trabalhadas em sala de aula, proporcionando assim, produções de dispositivos de qualidade para seus alunos.

\section{CONCLUSÕES}

Durante a construção deste dispositivo os produtores conseguiram explorar as ferramentas digitais de simples manuseio e acesso, além de compartilhar e convidar o público a vivenciar essa modalidade de ensino, que pode agregar conhecimento tanto para quem o produz, bem como para o público alvo.

Foi satisfatório poder apontar como essas ferramentas podem ser simples e bem úteis, e, demonstrar a facilidade no manuseio seja em recursos de áudio, vídeos, 
aplicativos como o rawshorts (na construção de vídeos), na publicação no YouTube e por fim das ferramentas disponíveis no G Suite For Education by Google.

A contribuição do professor orientador foi de suma importância, pois, a partir das técnicas realizadas em sala de aula, houve subsídio para que pudéssemos explorar mais ferramentas para produzir um dispositivo de qualidade, que pudesse ter um atual formato pedagógico e digital.

Concluímos por fim que, além da contribuição do professor orientador como mediador e facilitador no processo de desenvolvimento do dispositivo digital, a participação ativa de outros grupos de alunos foi muito importante, pois comentavam o que sentiam ao reproduzir o dispositivo, de forma crítica e construtiva.

\section{REFERÊNCIAS}

AGUIAR, Eliane Vigneron Barreto; FLÔRES, Maria Lucia Pozzatti. Objetos de aprendizagem: conceitos básicos. Objetos de aprendizagem: teoria e prática. Porto Alegre: Evangraf, p. 12-28, 2014.

ALMEIDA, M. E. B. Integração de tecnologias à educação: novas formas de expressão do pensamento, produção escrita e leitura. Formação de educadores a distância e integração de mídias. São Paulo: Avercamp, v. 268, 2007.

ANDERSEN, Elenice Larroza (Ed.). Multimídia digital na escola. Editora Paulinas, 2016.

BEIRA, D.; NAKAMOTO, P. A Formação docente inicial e continuada prepara os Professores para o Uso das Tecnologias de Informação e Comunicação (TICs) em sala de aula? In: Anais do Workshop de Informática na Escola. 2016. p. 825.

BRASIL, Parâmetros Curriculares Nacionais. Ensino médio. Brasília: Ministério da Educação, p. 1-71, 2000.

BURN, A.; DURRAN, J. Media literacy in schools: Practice, production and progression. Sage, 2007. 
CAStro, N. J., HAguenauer, C., Silva, E. M., AlveS, L. A., WAShington, M. G. M., CARVAlho, M. B., Pedroso, T. P. O estudo a distância com apoio da internet. Rio de Janeiro, v. 2, 2002.

CUNHA, D. O; BEZERRA, L. F; PINHO, J. F; ZOUAIN, D. M. Gestão Societal e Avaliação de Desempenho sob a Ótica de Servidores de uma Autarquia Federal. Rev. FSA, Teresina, v.17, n. 3, art. 4, p. 59-75, mar. 2020.

CUNHA, D. O.; OLIVEIRA, F. L.; BEZERRA, L. F.; SEVERIANO JUNIOR, E.; GONÇALVES, C. P. O Uso do E-Learning como Ferramenta de Ensino e Aprendizagem. Revista de Tecnologia Aplicada, v. 8, n. 3, p. 41-53, 2019.

MERABET, D. O. B.; SILVA, R. O.; GONÇALVES, C. P.; BARROS, D. F. Quão Plural é o Ensino de Marketing? Um Estudo Exploratório com Professores dos Cursos de Graduação em Administração. Administração: Ensino e Pesquisa, v. 21, n. 2, p. 147182, maio 2020.

MORGAdO, J. C., SANTOS, L. L. C. P., PARAÍSO, M. A. Estudos curriculares: um debate contemporâneo. 2013.

OCEPEK, U., BOSNIĆ, Z., ŠERBEC, I. N., \& RUGELJ, J. Exploring the relation between learning style models and preferred multimedia types. Computers \& Education, v. 69, p. 343-355, 2013.

ROSSONI, L.; GONÇALVES, C. P.; DA SILVA, M. P.; GONÇALVES, A. F. Mapeando Esquemas da Cultura Organizacional por Meio da Análise de Classes Correlacionais: Um Tutorial. Revista de Administração Contemporânea, v. 25, n. 1, p. e200096, 29 jul. 2020.

SEVERIANO JÚNIOR, E. Produtivismo Acadêmico como Vírus: Analisando processos sociais de influência. Orientador: Deborah Moraes Zouain. 2020. 72 f. Dissertação (Mestrado em Administração) - Escola de Ciências Sociais e Aplicadas, Universidade do Grande Rio Prof. José de Souza Herdy - UNIGRANRIO, Rio de Janeiro, 2020.

ZUNGUZE, M. C., NUNES, F. B., HANNEL, K., FRANCO, S. R. K., DE LIMA, J. V. Relação entre Estilos de Aprendizagem e forma de navegação em Apresentações Paralelas Multimídia. Informática na educação: teoria \& prática, v. 20, n. 1 jan/abr, 2017. 
DOI: http://dx.doi.org/10.5380/ef.v0i20

Recebido em: 17 de junho de 2020.

Aceito em: 14 de outubro de 2020. 